\title{
ADSORPTION MECHANISM OF BENZOTRIAZOLE FOR CORROSION INHIBITION OF COPPER-NICKEL ALLOY IN HYDROCHLORIC ACID
}

\author{
ANEES A. KHADOM ${ }^{1, *}$, APRAEL S. YARO ${ }^{2}$, AND ABDUL AMIR H. KADHUM ${ }^{1}$ \\ ${ }^{\prime}$ Department of Chemical and Process Engineering, Faculty of Engineering and Built Environment, Universiti Kebangsaan Malaysia, \\ Bangi, 43600, Selangor, Malaysia. \\ ${ }^{2}$ Chemical Engineering Department, College of Engineering, Baghdad University, Baghdad, Iraq. \\ (Received: September 14, 2009 - Accepted: December 11, 2009)
}

\begin{abstract}
The inhibition of copper corrosion by Benzotriazole (BTA) in $5 \% \mathrm{HCl}$ has been investigated by weight loss technique at different temperatures. Langmuir adsorption isotherm, Freundlich Adsorption Isotherm and Kinetic-Thermodynamic Model were used to describe the adsorption process depending on values of surface converge. Maximum value of surface converge was 0.998 for BTA at $35^{\circ} \mathrm{C}$ and $15 \mathrm{~g} / 1$ inhibitor concentration, while the lower value was 0.868 at $55{ }^{\circ} \mathrm{C}$ and $1 \mathrm{~g} / \mathrm{l}$ inhibitor concentration. The films formed on the copper-nickel alloy surface of BTA appeared to obey the Langmuir Adsorption Isotherm more than Freundlich adsorption isotherm. In the other hand, results showed that the Kinetic-Thermodynamic Model was unsuitable to fit the experimental data of the BTA of the present study.
\end{abstract}

Keywords: adsorption isotherms, corrosion inhibition, copper-nickel alloy, benzotriazole, inhibitor efficiency

\section{INTRODUCTION}

Copper and its alloys are commonly employed as a material in heating and cooling systems due to their good thermal conductivity and mechanical properties. Hydrochloric acid pickling is extensively used for the removal of rust and scale on heat transfer in several industrial processes. However, these systems should be regularly cleaned from carbonates and oxides that diminish their heating transmission. Diluted hydrochloric acid is used to clean these surfaces; a corrosion inhibitor is added to avoid the action of this acid on copper. Corrosion inhibitor is a chemical substance when it is added with little concentration to environment effectively checks, decreases or prevents the reaction of metal with environment ${ }^{1}$. It must be clearly understood that no universal corrosion inhibitor exists. Each inhibitor must be tailored to the specific corrosion problem that needs solution. While the use of inhibitors for some types of corrosion can be similar to other, this similarity must be treated as coincidence. Most inhibitors have been developed by empirical experimentation. Amines and triazoles derivatives have been reported to be very effective inhibitors for copper in acidic solutions s $^{2,3}$. The corrosion mechanism can vary considerably depending on the corrosive factors that are present. Similarly, the mechanism of inhibition will vary depending on the chemical nature of the inhibitor and the factor causing corrosion ${ }^{4}$. The most widely accepted postulated involves the formation of surface layers or films, which reduce the ease of access of the corrosive materials to the metal surface. Such scale can be formed naturally, or can be induced to form ${ }^{5}$. An equation relates the amount of substance attached to surface to its concentration in gas phase or in solution at fixed temperature, is known as an adsorption isotherms. The simplest isotherm was first obtained in 1916 by Irvan Langmuir ${ }^{6}$. This isotherm can be represented as;

$$
\theta=\frac{K C}{1+K C}
$$

Systems that obey this equation are often referred to ideal adsorption. Systems frequently deviate significantly from Langmuir equation. This may be because the surface is not uniform, and also there may be interaction between adsorbed molecules, a molecule attached to surface may make it more difficult, or less difficult, for another molecules to become attached to a neighboring site, and this will lead to deviation from the ideal adsorption equation. Nonideal system can sometimes be fitted to an empirical adsorption isotherm of Freundlich ${ }^{7}$

$$
\theta=K C^{n}
$$

$\mathrm{K}$, is equilibrium constant, $\mathrm{C}$ is inhibitor concentration, $\mathrm{n}$ is positive generally not integer constant, and $(\theta)$ is surface coverage. The Freundlich isotherm theory says that the ratio of the amount of solute adsorbed onto a given mass of sorbent to the concentration of the solute in the solution is not constant at different concentrations ${ }^{8}$.

Recent researches have looked into the action of adsorptive inhibitors from purely mechanistic kinetic point of view ${ }^{9,10}$. A kinetic-thermodynamic model for adsorption process at metal-solution interface has been suggested. This model has been tested on inhibition effect of number of open chain amines and one macrocyclic amine on the corrosion of steel in $\mathrm{H}_{2} \mathrm{SO}_{4}{ }^{10}$ and aluminum in $\mathrm{HCl}^{11}$. In this model, (y) is the number of inhibitor molecules occupying one active site. This model can be given by the following equation;

$$
\left(\frac{\theta}{1-\theta}\right)=K \cdot[C]^{y}
$$

Values of $y>1$ implies the formation of multilayers of inhibitor on the surface of metal. Values of $y<1$ mean a given inhibitor molecules will occupy more than one active site. $\mathrm{K}$, corresponding to adsorption isotherm is given by;

$$
K=K^{\left(\frac{1}{y}\right)}
$$

The present work is an attempt to study the corrosion inhibition mechanism of Benzotriazole for copper-nickel alloy in $5 \% \mathrm{HCl}$ at different temperatures. It has been reported by Loshkarav et al ${ }^{12}$ that, BTA exist as protonated species $\mathrm{C}_{6} \mathrm{H}_{6} \mathrm{~N}_{3}{ }^{+}$in acidic solution, as the undissociated compound $\mathrm{C}_{6} \mathrm{H}_{5} \mathrm{~N}_{3}$ in near neutral solutions, and as the simple anion $\mathrm{C}_{6} \mathrm{H}_{4} \mathrm{~N}_{3}$ - in alkaline solutions. The molecular structure of Benzotriazole is

\section{EXPERIMENTAL WORK}

The corrosion behavior of copper-nickel alloys, which used widely in many industrial equipments, was studied using weight loss in absence and presence Benzotriazole (BTA) in $5 \% \mathrm{HCl}$ solution at different temperature $\left(35,45\right.$, and $\left.55^{\circ} \mathrm{C}\right)$, and different inhibitor concentrations $(1,5,10$, and $15 \mathrm{~g} / 1)$.

Ring shape specimen of $\mathrm{Cu}-\mathrm{Ni}$ alloy with dimension $(2.22 \mathrm{~cm})$ outside diameter, $(1.5 \mathrm{~cm})$ width, and $(0.13 \mathrm{~cm})$ thickness, exposing a surface area of about $\left(10 \mathrm{~cm}^{2}\right)$ to corrosive media. Specimens were washed by detergent and flushed by tap water followed by distilled water, degreased by analar benzene 
and acetone, then annealed in vacuums to $600{ }^{\circ} \mathrm{C}$ for one hour and cooled under vacuum to room temperature. Before each run, specimens of $\mathrm{Cu}-\mathrm{Ni}$ were abraded in sequence using emery paper of grade number 220,320, 400, and 600 , then washed by running tap water followed by distilled water then dried by clean tissue, degreased with benzene, dried, degreased with acetone, dried, and finally left in desicater over silica gel. Weighing the specimen was carried out using 4 decimals digital balance and its dimensions were measured with vernier. The metal samples for weight loss runs were completely immersed in $250-\mathrm{cm}^{3}$ solution of corrodant contained in a conical flask. They were exposed for a period of three days at a desired temperature, acid concentration, and inhibitor concentration. Weight losses were determined in absence and presence of inhibitors. The data are expressed as mass loss per unit time per unit area; in the present work the units of corrosion rate were $\mathrm{g} / \mathrm{m}^{2}$.day (gmd). The chemical compositions of $\mathrm{Cu}-\mathrm{Ni}$ alloy were $(0.148 \% \mathrm{Sn}, 0.2 \% \mathrm{Fe}, 0.134 \% \mathrm{Zn}, 0.015 \% \mathrm{Al}$, $0.0003 \% \mathrm{P}, 0.5 \% \mathrm{Sb}, 0.0583 \% \mathrm{~Pb}, 0.0202 \% \mathrm{Si}, 0.017 \% \mathrm{~S}, 0.0056 \% \mathrm{As}, 10 \% \mathrm{Ni}$, and the reminder is $\mathrm{Cu}$ ).

\section{RESULTS AND DISCUSSIONS}

The corrosion rates of $\mathrm{Cu}-\mathrm{Ni}$ alloy in $5 \% \mathrm{HCl}$ acid solution as a function of temperature in absence and presence of different inhibitors concentrations are summarized in Table (1) through 15 runs using weight loss technique. The following equation was used to calculate the inhibitor efficiency:

$$
I E \%=\frac{W_{\text {uninibit }}-W_{\text {inhibit }}}{W_{\text {uninhibit }}} \times 100
$$

Where $\mathrm{W}_{\text {uninhibit }}$ and $\mathrm{W}_{\text {inhibit }}$ are the corrosion rates in absence and presence of inhibitor respectively. The primary step in the action of inhibitors in acid solution is generally agreed to be adsorption on the metal surface. This involves the assumption that the corrosion reactions are prevented from occurring over the area (or active sites) of the metal surface covered by adsorbed inhibitor species, whereas these corrosion reaction occurred normally on the inhibitorfree area ${ }^{13}$. Accordingly, the fraction of surface covered with inhibitor species $\left(\theta=\frac{\boldsymbol{E} \%}{100}\right)$ can follow as a function of inhibitor concentration and solution

temperature. The surface coverage $(\theta)$ data are very useful while discussing the adsorption characteristics. When the fraction of surface covered is determined as a function of the concentration at constant temperature, adsorption isotherm could be evaluated at equilibrium condition.

The corrosion rate increases with temperature increasing, generally, the addition of inhibitor reduces the corrosion rate, and the reductions depend on the concentration of inhibitors.

Table 1 Effect of Temperature and Inhibitor Concentration on the Corrosion of $\mathrm{Cu}-\mathrm{Ni}$ alloy in $5 \% \mathrm{HCl}$ Acid Solution.

\begin{tabular}{|c|c|c|c|c|c|}
\hline Run & Inhibitor & $\mathrm{C}(\mathrm{g} / \mathrm{l})$ & $\mathrm{T}\left({ }^{\circ} \mathrm{C}\right)$ & Rate (gmd) & IE $(\%)$ \\
\hline 1 & \multirow{3}{*}{ Nil } & \multirow{3}{*}{ Nil } & 35 & 12.5 & \\
\hline 2 & & & 45 & 15.87 & \\
\hline 3 & & & 55 & 20.83 & \\
\hline 4 & \multirow{12}{*}{ BTA } & 1 & \multirow{4}{*}{35} & 1.545 & 87.6 \\
\hline 5 & & 5 & & 0.35 & 97.2 \\
\hline 6 & & 10 & & 0.27 & 97.8 \\
\hline 7 & & 15 & & 0.0193 & 99.8 \\
\hline 8 & & 1 & \multirow{4}{*}{45} & 2.088 & 87.8 \\
\hline 9 & & 5 & & 0.695 & 95.6 \\
\hline 10 & & 10 & & 0.422 & 97.3 \\
\hline 11 & & 15 & & 0.105 & 99.3 \\
\hline 12 & & 1 & \multirow{4}{*}{55} & 2.543 & 86.8 \\
\hline 13 & & 5 & & 1.131 & 94.5 \\
\hline 14 & & 10 & & 0.668 & 96.8 \\
\hline 15 & & 15 & & 0.277 & 98.7 \\
\hline
\end{tabular}

The corrosion rate data can be used to analyze the adsorption mechanism, by using the value of $\theta$ as a function of inhibitor concentration. Rearranging Langmuir isotherm equation will give:

$$
\frac{C}{\theta}=\frac{1}{K}+C
$$

Equation (6) can be plotted as $\left(\frac{C}{\theta}\right)$ vs. C. The higher value of $\mathrm{K}$ indicates that the inhibitor is strongly adsorbed on the metal surface. From Table (2), and figure 1, the best fitting was obtained by Langmuir adsorption isotherm with high correlation coefficients (R) as compared with the other two models As shown in Figure 2, the lines deviate from linearity in the case of Freundlich adsorption isotherm and average value of $(n)$ was 0.0466 at different temperatures, which disagreed with typical value of $n=0.6{ }^{14}$. Figure 3 shows the kinetic thermodynamic model for the adsorption of BTA on $\mathrm{Cu}-\mathrm{Ni}$ surface. Generally, values of $\mathrm{K}$ obtained from the two-adsorption isotherms were in a good agreement with the values obtained from kinetic-thermodynamic models. The value of y was lower than unity indicating the formation of monolayer on the metal surface and this confirm the Langmuir behavior. Many of researchers apply adsorption isotherm in order to understand the mechanism of inhibitor adsorption, Ravera and Chavez ${ }^{15}$ studied the corrosion inhibition of copper in $\mathrm{H} 2 \mathrm{SO} 4$ acid, the corrosion rate data obey Langmuir - Freundlich isotherm with high correlation coefficient.

Table 2 Adsorption Constants and heats of adsorption from Langmuir

\begin{tabular}{|c|c|c|c|c|}
\hline \multicolumn{5}{|c|}{ Langmuir Isotherm Model } \\
\hline $\mathrm{T}\left({ }^{\circ} \mathrm{C}\right)$ & $\mathrm{K}(1 / \mathrm{g})$ & \multicolumn{2}{|c|}{$\Delta \mathrm{G}_{\mathrm{ads}}(\mathrm{kJ} / \mathrm{mol})}$. & $\mathrm{R}$ \\
\hline 35 & 5.586 & \multicolumn{2}{|c|}{-22.093} & 0.99993 \\
\hline 45 & 4.762 & \multicolumn{2}{|c|}{-22.389} & 0.999923 \\
\hline 55 & 4.762 & \multicolumn{2}{|c|}{-23.093} & 0.99989 \\
\hline \multicolumn{5}{|c|}{ Freundlich Isotherm Model } \\
\hline $\mathrm{T}\left({ }^{\circ} \mathrm{C}\right)$ & $\mathrm{K}(1 / \mathrm{g})$ & $\mathrm{n}$ & $\begin{array}{c}\Delta \mathrm{G}_{\mathrm{ads}}(\mathrm{kJ} / \\
\text { mol.) }\end{array}$ & $\mathrm{R}$ \\
\hline 35 & 0.883 & 0.048 & -17.37 & 0.9742 \\
\hline 45 & 0.87 & 0.049 & -17.894 & 0.99017 \\
\hline 55 & 0.879 & 0.043 & -18.485 & 0.9985 \\
\hline \multicolumn{5}{|c|}{ Kinetic-Thermodynamic Model } \\
\hline $\mathrm{T}\left({ }^{\circ} \mathrm{C}\right)$ & $\mathrm{K}(1 / \mathrm{g})$ & $\mathrm{y}$ & $\begin{array}{c}\Delta \mathrm{G}_{\mathrm{ads}}(\mathrm{kJ} / \\
\text { mol.) }\end{array}$ & $\mathrm{R}$ \\
\hline 35 & 3.67 & 1.31 & -21.018 & 0.8987 \\
\hline 45 & 5.53 & 1.003 & -22.784 & 0.9406 \\
\hline 55 & 8.803 & 0.813 & -24.768 & 0.95529 \\
\hline
\end{tabular}
Isotherm, Freundlich Isotherm and Kinetic-Thermodynamic Models.

Moreover, the essential characteristic Langmuir isotherm can be expressed in term of a dimensionless separation factor, $\mathrm{R}_{\mathrm{L}}{ }^{16}$, which describes the type of isotherm and defined by:

$$
R_{L}=\frac{1}{1+K C}
$$

The smaller $R_{t}$ value indicates a highly favorable adsorption. If $R_{L}>1$ unfavorable, $\mathrm{R}_{\mathrm{L}}=1$ linear, $0<\mathrm{R}_{\mathrm{L}}<1$ favorable, and if $\mathrm{R}_{\mathrm{L}}=0$ irreversible. Table 3 gives the estimated values of $R_{L}$ for BTA at different concentrations. It was found that all $\mathrm{R}_{\mathrm{L}}$ values are less than unity conforming that the adsorption processes is favorable. The values of $\mathrm{R}_{\mathrm{L}}$ did not change as the temperature increased from 45 to $55^{\circ} \mathrm{C}$. This is because that the $\mathrm{K}$ (equilibrium constant) value is unchanged, and this mean that the amount of adsorbed inhibitor equal to desorbed one, in other words, the equilibrium process may be reached.

From the values of equilibrium constants, which obtained from different isotherms, the values of heat of adsorption, $\Delta \mathrm{G}_{\mathrm{ad} \times}$, can be obtained using the following equation ${ }^{17}$

$$
K=\left(\frac{1}{55.55}\right) \exp \left(-\frac{\Delta G_{a d s}}{R T}\right)
$$


The value of (55.5) is the water concentration in solution expressed in $\mathrm{M}$, (i.e., $\sim 1000 \mathrm{~g} / \mathrm{l}$ ). $\mathrm{R}$ and $\mathrm{T}$ are the gas constant and absolute temperature respectively.

Table 3 The values of dimensionless separation factor $R_{L}$ for BTA at various concentrations and temperatures.

\begin{tabular}{|c|c|c|}
\hline BTA $(\mathrm{g} / \mathrm{l})$ & Temperature $\left({ }^{\circ} \mathrm{C}\right)$ & $\mathrm{R}_{\mathrm{L}}$ \\
\hline 1 & 35 & 0.151 \\
5 & & 0.0345 \\
10 & & 0.0175 \\
15 & & 0.0117 \\
\hline 1 & 45 & 0.1735 \\
5 & & 0.0403 \\
10 & & 0.0205 \\
15 & & 0.0138 \\
\hline 1 & & 0.1735 \\
5 & & 0.0403 \\
10 & & 0.0205 \\
15 & & 0.0138 \\
\hline
\end{tabular}

The values of $\Delta \mathrm{G}_{\text {ads }}$, heat of adsorption were given in tables (2). The values of $\Delta \mathrm{G}_{\text {ads }}$ for BTA inhibitor were in the range of $(-17.37$ to $-24.76 \mathrm{~kJ} / \mathrm{mol}$.), which indicate the good adsorption of BTA inhibitor to the metal surface. The negative values of $\Delta \mathrm{G}_{\mathrm{ads}}$ ensures the spontaneity of the adsorption process and stability of the adsorbed layer on the metal surface. Generally, value of $\Delta \mathrm{G}_{\text {ads }}$ up to $-20 \mathrm{~kJ} \cdot \mathrm{mol}^{-1}$ is consistent with electrostatic interaction between the charged molecules and the charged metal (physisorption) while those around $-40 \mathrm{~kJ} \cdot \mathrm{mol}^{-1}$ or higher than that are associated with chemisorptions as a result of sharing or transferring of electrons from the organic molecules to the metal surface to form a coordinate type of bond ${ }^{18,19}$. While other researchers suggested that the range of $\Delta \mathrm{G}_{\text {ads }}$ of chemical adsorption processes for organic inhibitor in aqueous media lies between $\left(-21 \text { to }-42 \mathrm{~kJ} \mathrm{~mol}^{-1}\right)^{20}$. Therefore, in the present work, the value of $\Delta \mathrm{G}_{\text {ads }}$ has been considered within the range of chemical adsorption.

\section{CONCLUSION}

The corrosion rate of $\mathrm{Cu}-\mathrm{Ni}$ alloy in $5 \% \mathrm{HCl}$ acid solution, increased with increasing of temperature, and decreased with increasing of inhibitor concentration. BTA was very effective inhibitor with maximum inhibitor efficiency of $99.8 \%$ at $35^{\circ} \mathrm{C}$ and $15 \mathrm{~g} / \mathrm{l}$ inhibitor concentration, while the lower value was $86.8 \%$ at $55{ }^{\circ} \mathrm{C}$ and $1 \mathrm{~g} / 1$ inhibitor concentration. BTA adsorption on the metal surface strongly obeyed Langmuir adsorption isotherm more than Freundlich adsorption isotherm. In the other hand, the values of y (i.e. the number of inhibitor molecules occupying one active site on the metal surface) obtained from the Kinetic-Thermodynamic Model were near unity, which indicate the formation of monolayer on the metal surface. Values of heat of adsorption $\Delta \mathrm{G}_{\text {ads }}$ were high and negative, which indicate the strong binding of inhibitor to the metal surface.

\section{ACKNOWLEDGMENT}

This work was supported by Universiti Kebangsaan Malaysia (Grant number: UKM-OUP-NBT-26-120/2008) which is gratefully acknowledged.

\section{Nomenclature}

$\mathrm{C}: \quad$ inhibitor concentration $\left(\mathrm{g} . \mathrm{l}^{-1}\right)$

IE\%: inhibitor efficiency

$\mathrm{K}$ : equilibrium constant $\left(1 . \mathrm{g}^{-1}\right)$

$\mathrm{n}$ : Freundlich isotherm constant

$\mathrm{R}$ : $\quad$ gas constant $\left(8.314 \mathrm{~J} . \mathrm{mol}^{-1} \cdot \mathrm{K}^{-1}\right)$

$\mathrm{R}_{\mathrm{L}}$ : dimensionless separation factor

$\mathrm{T}: \quad$ temperature $\left({ }^{\circ} \mathrm{C}\right)$

$\mathrm{W}_{\text {uninhibit }}$ and $\mathrm{W}_{\text {inhibit }}$ :

inhibitor respectively (gmd).

$\Delta \mathrm{G}_{\mathrm{ads}}$ : heat of adsorption $\left(\mathrm{kJ} \cdot \mathrm{mol}^{-1}\right)$

$\Theta: \quad$ ads $\quad$ surface coverage.

\section{REFERENCES}

1. Z. Da-Quan, C. Qi-Rui, G. Li-Xin, and Kang Yong Lee, Corros. Sci., 50 (2008) 3615

2. M. Sherif, M. Erasmus, and D. Comins, J. Colloid. Interface Sci., 311 (2007) 144.

3. M. Sherif, S. Park, J. Electrochim Acta, 51 (2006) 4665.

4. Sastri S, (2001) Corrosion Inhibitors principles and applications. Johan Wiley \& Sons publisher, USA.

5. A. Fiala, A. Chibani, A. Darchen, Boulkamh, and K. Djebbar, Appl. Surf. Sci., 253 (2007) 9347.

6. S. El-Egamy, Corros. Sci., 50 (2008) 928

7. K. Nageh, Appl. Surf. Sci., 253 (2007) 4570.

8. E. Unuabonah, B. Olu-Owolabi, O. Adebowale, and E. Ofomaja Colloids and Surfaces A: Physicochem Eng Aspects, 292 (2007) 202.

9. S. Fouda, A. Al-Sarawy, F. Ahmed, and M. El-Abbasy, Corros. Sci., 51 (2009) 485.

10. A. El-Awady, A. Abd-El-Nabey, and G. Aziz, J. Electo. Chem. Soc., 139 (1992) 2149

11. A. El-Awady, A. Abd-El-Nabey and G. Aziz, J. Chem. Soc. Faraday. Trans., 89 (1993) 795.

12. Loshkarev, Mardvchenka, and Yushohenka Metal Abstr, 35-0142, p.112 (1974).

13. Shereir L (1977) Corrosion. vol. 2, $2^{\text {nd }}$ edition, Newnes-Butterworths, London.

14. A. Clark, The Theory of Adsorption and Catalyst. Academic Press, New York, 1970.

15. S. B. Ravera, M. A. Chavez, Journal of the Chilean Chemical Society, $\mathbf{5 0}$ (2005) 739.

16. L. Mall, C. Srivastava, K. Agrwal, and M. Mishra, Colloids Surf A: Physicochem Eng Aspects, 264 (2005) 17.

17. M. Scendo, Corros. Sci., 49 (2007) 3953.

18. A. Umoren, and E. Ebenso, Mate.r Chem. Phys., 106 (2007) 387.

19. Umoren A, Obot B, and Ebenso E, E-journal Chem., 5 (2008) 355.

20. W. Damaskin, A. Pietrij, W. Batrakow, Adsorption of Organic Compounds on Electrode. Plenum Press, New York, 1971. 